\title{
Natural Fibers, Bio- and Nanocomposites
}

\author{
Susheel Kalia, ${ }^{1}$ Luc Avérous, ${ }^{2}$ James Njuguna, ${ }^{3}$ Alain Dufresne, ${ }^{4}$ and Bibin Mathew Cherian ${ }^{5}$ \\ ${ }^{1}$ Department of Chemistry, Shoolini University of Biotechnology and Management Sciences, \\ District Solan (Himachal Pradesh), Bajhol-173 229, India \\ ${ }^{2}$ LIPHT-ECPM, EAC (CNRS) 4375, University of Strasbourg, 25 rue Becquerel, 67087 Strasbourg Cedex 2, France \\ ${ }^{3}$ School of Applied Sciences, Cranfield University, Bedfordshire MK43 OAL, UK \\ ${ }^{4}$ Grenoble Institute of Technology, The International School of Paper, Print Media and Biomaterials (Pagora), \\ BP 65, 38402 Saint Martin d'Hères Cedex, France \\ ${ }^{5}$ Department of Natural Resources, Sao Paulo State University (UNESP), Botucatu 18610-307, SP, Brazil
}

Correspondence should be addressed to Susheel Kalia, susheel_kalia@yahoo.com

Received 12 October 2011; Accepted 12 October 2011

Copyright (C) 2011 Susheel Kalia et al. This is an open access article distributed under the Creative Commons Attribution License, which permits unrestricted use, distribution, and reproduction in any medium, provided the original work is properly cited.

Natural fibers have received great interest as reinforcing material for polymer-based matrices because of the environmental issues in combination with their lowcost and some intrinsic interesting properties (density, shape ratio, mechanical behavior). From natural fibers, we can obtain cellulose whiskers in a multistep process. Cellulose nanofibers reinforced polymer composites is a fast-growing area of research because of their enhanced mechanical, thermal, and biodegradation properties. Nanocomposites based on cellulose nanofibers are increasingly regarded as an alternative to conventional composites. The properties of nanocomposites depend not only on the properties of their individual constituents but also on their morphology and interfacial (matrix/nanofiller) characteristics. This rapidly expanding field is generating many exciting new materials with novel properties. This special issue will be interesting for researchers working in the field of natural fibers, isolation of cellulose nanofibers, pretreatments of natural fibers and their application as reinforcement in bio- and nanopolymer composites.

The first paper of this special issue "Cellulose-based bio- and nanocomposites: A review," is an overview, which reviewed the surface modification of cellulose fibers by various methods. Applications of cellulose nanofibers for the development of composites are discussed in this review. Processing methods, properties, and various applications of nanocellulose and cellulosic composites are also discussed.
The second paper of this special issue "Kenaf bast Fibers-Part I: Hermetical alkali digestion" developed a hermetical alkali digestion process to obtain single cellulosic fibers from kenaf bast. Hermetical alkali digestion process effectively removed the lignin and hemicelluloses from kenaf bast fibers at $160^{\circ} \mathrm{C}$. The $\alpha$-cellulose content of the fibers was $92 \%$. The increase of cellulose content of the digested fibers resulted in an improved fiber surface hardness and elastic modulus. The digestion temperature had a significant effect on tensile modulus and tensile strength properties of the kenaf fiber.

The third paper "Isolation of cellulose nanofibers: Effect of biotreatment on hydrogen bonding network in wood fibers" briefly describes a novel enzymatic fiber pretreatment developed to facilitate the isolation of cellulose microfibrils and explores the effectiveness of biotreatment on the intermolecular and intramolecular hydrogen bonding in the fiber. Hydrogen bond-specific enzyme and its application in the isolation of new generation cellulose nanofibers can be a huge leap forward in the field of nanobiocomposites.

Paper four of this issue "Effect of sisal fiber surface treatment on properties of sisal fiber reinforced polylactide composites" dealt with the modification of sisal fiber using two different macromolecular coupling agents. Sisal fiberreinforced polylactide composites that were prepared by injection molding. It has been shown that surface-treatment of sisal fiber increased the mechanical properties for composites systems. 
In paper five "Time effects on morphology and bonding ability in mercerized natural fibers for composite reinforcement," kenaf fibers were alkali treated, and the surface and morphology were analyzed to determine how treatment time affected the bonding sites in natural fibers. Tensile testing of fibers reported a $61 \%$ increase in strength and a $25 \%$ increase in modulus for fibers treated for 16 hours. The increase in tensile properties was assumed to result from increased intermolecular interaction and increased crystallinity in cellulose.

Paper six of this issue "Role of polysaccharides on mechanical and adhesion properties of flax fibres in flax/PLA biocomposite" dealt with the effect of alkali and enzymatic treatments on morphology, mechanical, and adhesion properties of flax fiber. This paper highlights the important role of amorphous polymers, hemicelluloses, and pectin in the optimization of the adhesion and mechanical properties of flax fibers in biocomposites systems.

In paper seven "Mechanical and Thermal Behaviour of Ecofriendly Composites Reinforced by Kenaf and Caroà Fibers," two kinds of environmental friendly composites were prepared reinforced by Caroà and Kenaf fibers. The obtained composites were compared in terms of moisture tolerance, thermal and mechanical properties, and thermoregulation ability.

In paper eight of this special issue "Effect of different parameters on mechanical and erosion wear behavior of bamboo fiber-reinforced epoxy composites," an attempt has been made to study the utilization potential of bamboo fiber in polymer composites and the effect of various parameters on mechanical and erosion wear performance of bamboo fiber-reinforced epoxy composites.

The ninth paper of this special issue "Manufacturing and structural feasibility of natural fiber-reinforced polymeric structural insulated panels for panelized construction" mainly focuses on the manufacturing feasibility and structural characterization of natural fiber-reinforced structural insulated panels (NSIPs) using natural fiber reinforced polymeric (NFRP) laminates as skin. The natural fibers were bleached before their use as reinforcement.

The tenth paper "Natural fibre-reinforced biofoams" dealt with natural fiber reinforced biofoams using starch and polylactic acid. This paper investigates the improvement of their morphology and properties through processing and materials parameters. The influence of a fiber surface treatment was investigated for both foams.

The eleventh paper "Kenaf bast fibers-Part II: Inorganic nanoparticle impregnation for polymer composites" used an inorganic nanoparticle impregnation (INI) technique to improve the compatibility between kenaf bast fibers and polyolefin matrices. The final paper of this special issue "A study of nanoclay reinforcement of biocomposites made by liquid composite molding" reports on a study of biobased composites reinforced with nanoclay particles. A soy-based unsaturated polyester resin was used as synthetic matrix, and glass and flax fiber fabrics were used as reinforcement. The last paper "A study of nanoclay reinforcement of biocomposites made by liquid composite molding" aims to improve mechanical and flammability properties of reinforced composites by introducing nanoclay particles in the unsaturated polyester resin.

Susheel Kalia

Luc Avérous

James Njuguna

Alain Dufresne

Bibin Mathew Cherian 

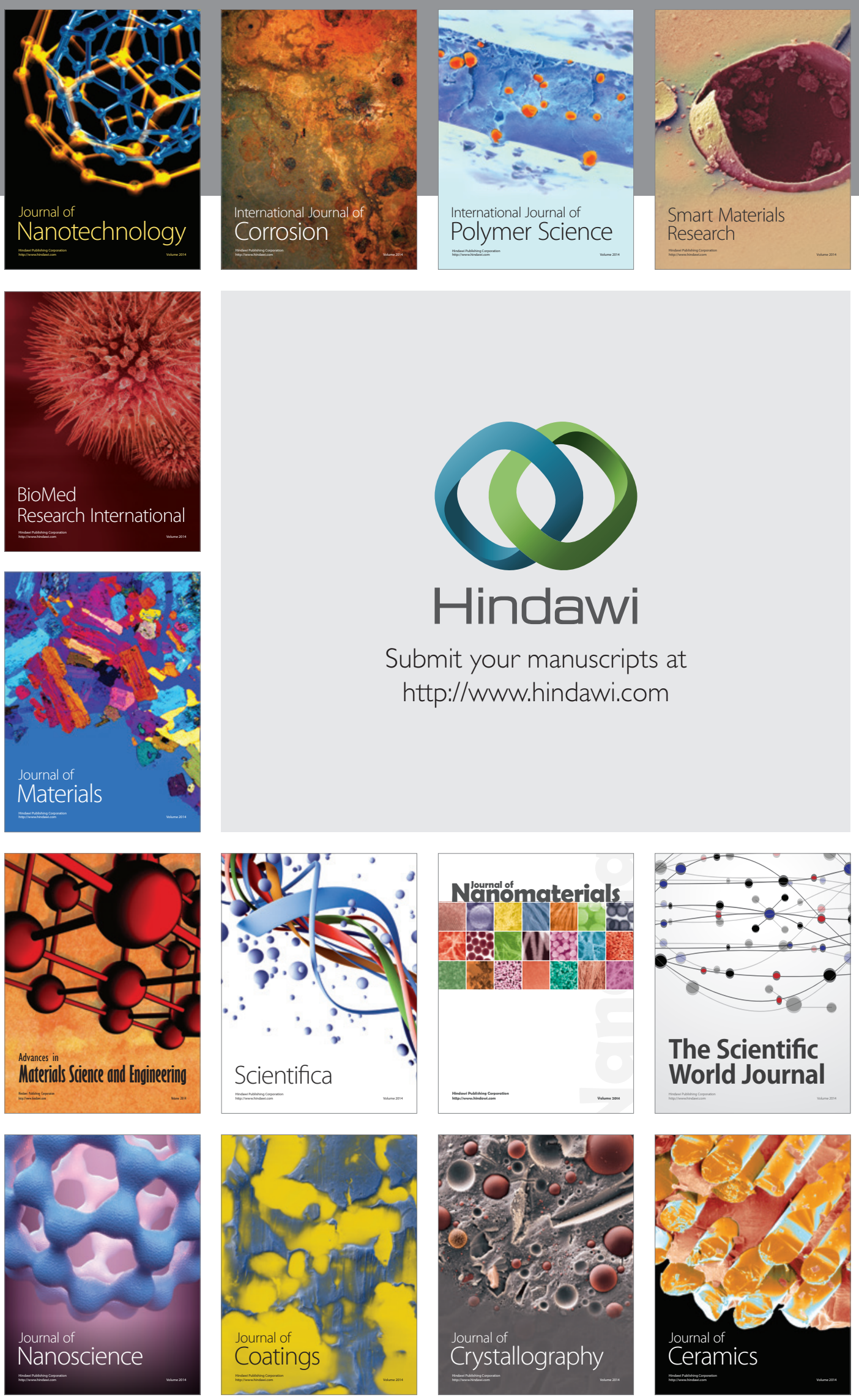

The Scientific World Journal

Submit your manuscripts at

http://www.hindawi.com

\section{World Journal}

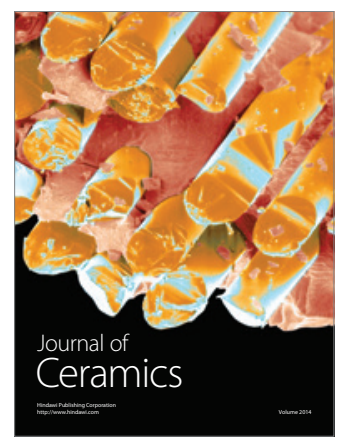

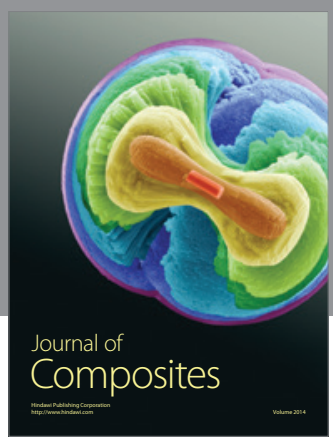
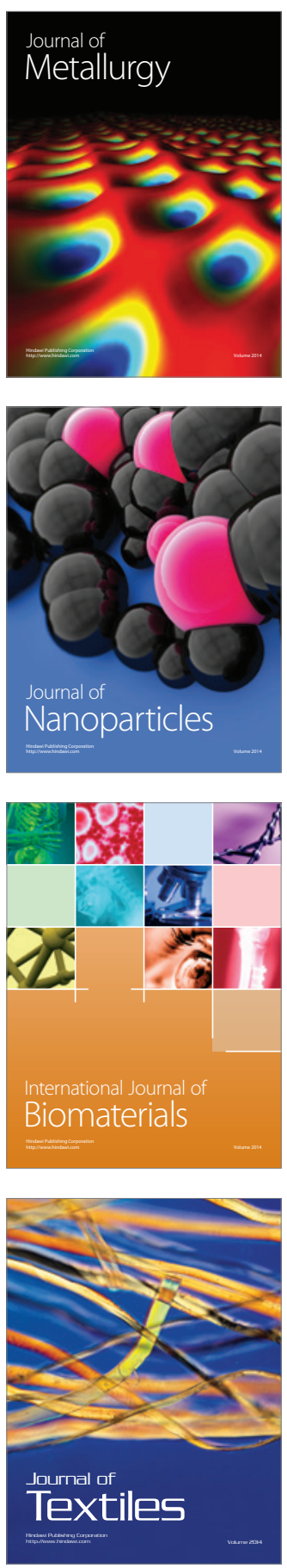